\title{
Medicina Baseada em Consciência Social
}

\author{
Social Awareness-Based Medicine
}

Fernando Osni Machado, PhD

As doenças infecciosas, resultando em sepse grave e choque séptico, tem sido um grande desafio para a Medicina nas últimas décadas. Enorme tem sido o impacto sobre a vida dos seres humanos, pois a despeito dos avanços tecnológicos obtidos nos últimos anos, as taxas de morbidade e mortalidade decorrentes de sepse continuam muito elevadas. Quando a definição etiológica do quadro infeccioso é possível, com a identificação de um agente microbiológico, a mortalidade nos quadros de sepse grave alcança taxas de até $50 \%$, mas quando esta definição etiológica não é possível, a mortalidade alcança até $66 \%{ }^{1}$. Sasse e col. em artigo publicado em 1995, mostrou que a mortalidade nas unidades de terapia intensiva (UTI) foi de $37 \%$, mas apenas $49 \%$ dos pacientes sobreviveram à internação hospitalar e $72 \%$ faleceram após um ano da alta hospitalar ${ }^{2}$. Estudos mais recentes, mostram taxas de mortalidade igualmente elevadas e o mais preocupante é o aumento na incidência de sepse grave de 1,5\% ao ano ${ }^{3,4}$. No Brasil, dois estudos mostraram a elevada ocorrência e taxas de mortalidade tão altas como $34,4 \%$ na sepse grave e $65,3 \%$ no choque séptico ${ }^{5,6}$. Este quadro dramático tem sido motivo de significativo esforço, dos médicos e da indústria farmacêutica, na busca de alternativa terapêutica que possa diminuir os efeitos da sepse ${ }^{7-12}$, mas o limitado benefício alcançado não parece estar relacionado ao investimento em novos medicamentos.

As incertezas no diagnóstico de sepse e suas diferentes gravidades justificaram uma conferência médica de alto nível em 1992, que resultou em uma padronização permitindo melhor comparar resultados de estudos clínicos realizados em diferentes centros de pesquisa ${ }^{13}$. Nos últimos anos, um novo fármaco chamado drotre-

Médico, Diretor Médico do Serviço de Terapia Intensiva do Hospital Universitário da Universidade Federal de Santa Catarina (UFSC); ExDiretor Geral do Hospital Universitário da UFSC; Mestre em Medicina Interna da UFSC; Doutor em Medicina da USP; Professor Adjunto II da UFSC

E-mail: fernandoo.machado@gmail.com

(C)Associação de Medicina Intensiva Brasileira, 2007 cogina alfa-ativada, vem sendo utilizado por muitos pesquisadores em todo o mundo, inclusive no Brasil, no tratamento de choque séptico e sepse grave, mas nos resultados dos estudos alguns apresentam aparente eficiência e outros com questionável eficácia, não conseguiram convencer toda a comunidade médica pelas pequenas evidências dos efeitos benéficos, pelo risco de efeitos colaterais graves e potencialmente fatais, bem como pelo alto custo.

Nos últimos meses, foram publicados estudos, realizados no Canadá e na Itália por autores independentes, não vinculados à indústria farmacêutica que apresentaram resultados pondo em dúvida a continuidade da prescrição da drotrecogina alfa-ativada ${ }^{14,15}$.

A dúvida quanto a real utilidade deste fármaco, bem como a influência da indústria farmacêutica na produção de diretrizes terapêuticas está fartamente discutida em diversos artigos científicos ${ }^{16-18}$.

Lembramos que o custo do tratamento por paciente, considerando pacientes com peso entre 60 e $120 \mathrm{~kg}$, pode variar de $\mathrm{R} \$ 46.300,00$ a $\mathrm{R} \$ 92.600,00^{19}$. Citam os artigos que justificam o uso de drotrecogina alfa-ativada, que em 20 pacientes, um pode ter o benefício de estar vivo ao final do $28^{\circ}$ dia da internação ${ }^{20-22}$. Estes artigos não informaram sobre a mortalidade que ocorre após este período, nem citaram a qualidade de vida dos sobreviventes ${ }^{20-22}$.

Outro estudo recente (ADDRESS), cujos autores não omitem a relação com a indústria farmacêutica, fabricante do fármaco em questão, limitou-se a concluir que ele pode ser seguro, mas não conseguiu demonstrar benefícios relativos à morbidade e mortalidade ${ }^{21}$. Neste estudo a mortalidade no $28^{\circ}$ dia e após um ano, não foi diferente nos pacientes tratados com a drotrecogina alfa-ativada, quando comparados com os pacientes tratados com placebo ${ }^{23}$.

Diante do exposto, tomando por base 20 pacientes com peso médio de $80 \mathrm{~kg}$, seriam necessários $\mathrm{R} \$$ 1.540.000,00, para oportunizar apenas um paciente a probabilidade de sobreviver ao $28^{\circ}$ dia de internação. Para permitir uma análise mais profunda e socialmente racional, informamos que o Hospital Universitário da 
Universidade Federal de Santa Catarina atende mensalmente mais de 20.000 pacientes externos, (13.000 pacientes ambulatoriais 8.000 pacientes em emergência); assiste mais de 800 pacientes internados; realizam mais de 200 cirurgias de grande porte; realiza 150 partos; assiste a 30 pacientes em UTI adulta e 20 pacientes em UTI neonatal, entre outros procedimentos. Para dar suporte a todas as realizações descritas, o HU-UFSC dispõe de $\mathrm{R} \$ 900.000,00$ mensais para material de consumo (medicamentos, seringas, agulhas, fios cirúrgicos, cateteres, sondas, etc.). Para a aquisição de medicamentos, o orçamento mensal do HUUFSC é de apenas $R \$ 150.000,00^{24}$.

Considerando a falta de evidências sobre o efetivo benefício deste fármaco e considerando a realidade financeira da saúde pública no Brasil, que impõe aos gerentes e gestores a utilização dos limitados recursos para garantir a realização dos procedimentos diagnósticos e terapêuticos, que já tiveram comprovado efetividade em benefício da maior parcela possível da população, manifesto minha opinião contrária à prescrição de drotrecogina alfa-ativada no sistema de saúde público brasileiro. De igual modo, acredito que o sistema de saúde complementar deve analisar com mais profundidade e racionalidade, para verificar se diante da fraca evidência de eficácia do fármaco em questão, justifica-se o investimento de somas tão elevadas nesta terapêutica, ou será que não haveria melhor aplicação para tais recursos em benefício do conjunto de todos os segurados?

\section{REFERÊNCIAS}

01. Brun-Buisson C, Doyon F, Carlet $\mathrm{J}$ et al - Incidence, risk factors, and outcome of severe sepsis and septic shock in adults. A multicenter prospective study in intensive care units. JAMA, 1995;274:968-974.

02. Sasse KC, Nauenberg E, Long A et al - Long-term survival after intensive care unit admission with sepsis. Crit Care Med, 1995;23:1040-1047.

03. Angus DC, Linde-Zwirble WT, Lidicker $\mathrm{J}$ et al - Epidemiology of severe sepsis in the United States: Analysis of incidence, outcome, and associated costs of care. Crit Care Med, 2001;29:1303-1310.

04. Martin GS, Mannino DM, Eaton S, Moss M - The Epidemiology of Sepsis in the United States from 1979 through 2000. N Engl J Med, 2003;348:1546-1554.

05. Silva E, Pedro Mde A, Sogayar AC et al - Brazilian Sepsis Epidemilogycal Study (BASES study). Crit Care, 2004;8:R251-R260.
06. Sales Jr JAL, David CM, Hatum R et al - Sepse Brasil: estudo epidemiológico da sepse em unidades e terapia intensiva brasileiras. RBTI, 2006;18:9-17.

07. Greenberg RN, Wilson KM, Kunz AY et al - Observations using antiendotoxin antibody (E5) as adjuvant therapy in humans with suspected, serious, gram-negative sepsis. Crit Care Med, 1992;20:730-735.

08. Gorelick KJ, Jacobs $\mathrm{R}$, Chmel $\mathrm{H}$ et al - Results of a randomized multicenter trial of efficacy of an antiendotoxin monoclonal antibody (XomaE5) in patients with suspected gram-negative sepsis. In: Proceedings of the $29^{\text {th }}$ Interscience Conference on Antimicrobial Agents and Chemotherapy, Houston, TX. Washington, DC, American Society for Microbiology, 1989;154.

09. Ziegler EJ, Fisher CJ Jr, Sprung CL et al - Treatment of gram-negative bacteremia and septic shock with HA-1A human monoclonal antibody against endotoxin. A randomized, double-blind placebo-controlled trial. The HA-1A Sepsis Study Group. N Engl J Med, 1991;324:429-436.

10. Greenman RL, Schein RM, Martin MA et al - A controlled clinical trial of E5 murine monoclonal $\operatorname{lgM}$ antibody to endotoxin in the treatment of gram-negative sepsis. The XOMA Sepsis Study Group. JAMA, 1991;266:1097-1102.

11. Wortel $\mathrm{CH}$, von der Mohlen MA, van Deventer SJ et al - Effectiveness of a human monoclonal anti-endotoxin antibody ( $\mathrm{HA}-1 \mathrm{~A})$ in gram-negative sepsis: relationship to endotoxin and cytokine levels. J Infect Dis, 1992;166:1367-1374.

12. Daifuku R, Panacek EA, Haenftling $\mathrm{K}$ et al - Pilot study of anti-lipopolysaccharide human monoclonal antibody MAB-T88 in patients with gramnegative sepsis. Human Antibodies Hybridomas, 1993;4:36-39.

13. Members of the American College of Chest Physicians/Society of Critical Care Medicine Consensus Conference Committee: American College of Chest Physicians/Society of Critical Care Medicine Consensus Conference: Definitions for sepsis and organ failure and guidelines for the use of innovative therapies in sepsis. Crit Care Med, 1992;20:864-874

14. Bertolini G, Rossi C, Anghileri A et al - Use of Drotrecogin alfa (activated) in Italian intensive care units: the results of a nationwide survey. Intensive Care Med, 2007;33:426-434.

15. Kanji S, Perreault MM, Chant $\mathrm{C}$ et al - Evaluating the use of Drotrecogin alfa (activated) in adult severe sepsis: a Canadian multicenter observational study. Intensive Care Med, 2007;33:517-523.

16. Wiedermann CJ - Bioethics, the Surviving Sepsis Campaign, and the industry. Wien Klin Wochenschr, 2005;117:442-444.

17. Eichacker $P Q$, Natanson $C$, Danner RL - Surviving sepsis-practice guidelines, marketing campaigns, and Eli-Lilly. N Engl J Med, 2006;355:1640-1642.

18. Singer $M$ - The Surviving Sepsis guidelines: evidence-based... or evidence-biased? Crit Care Resusc, 2006;8:244-245.

19. Lista de preços atualizada, Revista ABCFARMA, 2007;5:214.

20. Bernard GR, Vincent JL, Laterre PF et al - Efficacy and safety of recombinant human activated protein $\mathrm{C}$ for severe sepsis. N Engl J Med, 2001;344:699-709.

21. Garber G, Gibney R, Light B et al - Guidance on patient identification and administration of recombinant human activated protein $\mathrm{C}$ for the treatment of severe sepsis. Can J Infect Dis, 2002;13:361-372.

22. Vincent JL, Bernard GR, Beale R et al - Drotrecogin alfa (activated) treatment in severe sepsis from the global open-label trial ENHANCE: further evidence for survival and safety and implications for early treatment. Crit Care Med, 2005;33:2266-2277.

23. Laterre PF, Abraham E, Janes JM et al - ADDRESS (ADministration of DRotrecogin alfa [activated] in Early stage Severe Sepsis) long-term follow-up: one-year safety and efficacy evaluation. Crit Care Med, 2007;35:1457-1463.

24. Relatórios mensais movimentação financeira - Hospital Universitário da UFSC. Diretoria de Administração, HU-UFSC, 2007. 